\title{
Technique to Prevent Metal Deposition on Optical Components in Space Diode Laser Welding for Space Applications*
}

\author{
By Yoshikazu Suita, Kenji Tanaka, Masato Ohtani, Shinichiro Shobako, \\ Noboru TERAJIMA and Nobuaki HIRAOKA \\ Department of Electro-Mechanical Systems Engineering, Kagawa National College of Technology, Takamatsu, Japan
}

(Received April 22nd, 2010)

\begin{abstract}
In future space developments, welding in space may be required for repairs to the International Space Station and for constructing lunar bases and space structures. This paper describes the results of applying the space diode laser (DL) welding process, which the authors proposed in 2002. To use the DL welding process in space, it is necessary to prevent metal deposition on optical devices. We investigated a technique for preventing metal deposition in which the nozzle is installed at optical devices and a shielding gas is ejected from the nozzle outlet. Metal deposition can be reduced by blowing inert gas from the nozzle. The shielding gas argon completely prevents metal deposition on optical devices when the argon pressure in the nozzle is over $19.9 \mathrm{~Pa}$ and argon is ejected from the nozzle outlet.
\end{abstract}

Key Words: $\quad$ Process \& Production, Space Diode Laser Welding, Metal Deposition, Optical Device, Stainless Steel

\section{Introduction}

On July 19, 2009, at 11:23 (Japanese Standard Time), long-stay International Space Station (ISS) astronaut Kouichi Wakata deftly operated the robot arm to install the Exposed Facility, launched on the space shuttle Endeavor, on the Pressurized Module of the Japanese Experiment Module (JEM), “Kibo”. 27 years after its conception, Japan's prized space experimental test facility "Kibo" was completed.

Due to the long operational period (approximately 10 years) of the ISS, it is anticipated that welding technology will be required to repair and refurbish damage from collisions with space debris and meteorites. Space welding technology is also expected to be used in the construction of space structures in space and lunar base structures. Research into space welding technology commenced in about 1960 with electron beam welding research ${ }^{1-3)}$ by the former Soviet Union and the US; Japan also conducted research in the 1990s. ${ }^{4)}$ To confirm whether welding technology could be applied to repairs on the ISS, NASA planned to install electron beam welding equipment developed by the Paton Electric Welding Institute on the space shuttle and to perform welding experiments in space in October 1997. However, due to problems with the space shuttle schedule and the ability to ensure the safety of astronauts, it was decided to postpone the welding experiments indefinitely. ${ }^{5}$ )

Arc welding ${ }^{6-9)}$ and laser welding have also been investigated with an eye to space applications. Nd-YAG laser welding ${ }^{10)}$ was studied in the US in 1991, but there were problems with the bulkiness and weight of the equipment,

(C) 2011 The Japan Society for Aeronautical and Space Sciences

*Translated from Journal of the Japan Society for Aeronautical and Space Sciences, Vol. 58, No. 673, 2010, pp. 54-59. Presented at The 49th Space Sciences and Technology Conference, November 9th, 2005 and with its low efficiency. There has been remarkable progress in recent years in increasing the output of semiconductor lasers (also known as diode lasers, (DL)) and fiber lasers. The advantages of these lasers include high efficiencies, compactness, and low weight. They have the potential to be used in constructing and repairing space structures in space. We have proposed a space DL welding process ${ }^{11,12}$ ) that exploits these advantages. However, various problems are encountered with laser welding in low pressure environments, including transmittance reduction in optical components, degradation, and damage to optical devices due to metal deposition during welding. ${ }^{13}$ )

This study investigated methods to overcome the various problems associated with metal deposition on optical devices. Methods were studied to control or prevent metal deposition on a quartz plate installed to protect the optical components of the laser emitter (e.g., the focusing unit and quartz laser window). The results show that metal deposition on the quartz plate can be prevented by using a method in which a nozzle is installed on the laser emitter, and a very low flow of shielding gas is supplied to the nozzle and blown from the nozzle outlet. This technique for preventing metal deposition on optical components is reported because it raises the possibility that space DL welding proposed by us can be used in space.

\section{Experimental Apparatus and Methods}

\subsection{Experimental apparatus}

Figure 1 shows the high-vacuum DL welding experimental system used in this experiment. It comprises a vacuum system (vacuum chamber capacity: $0.17 \mathrm{~m}^{3}$, operating pressure: $\left.6 \times 10^{-6} \mathrm{~Pa}\right)$, a $2.5 \mathrm{~kW}$ continuouswave direct $\mathrm{DL}$ equipment, and a control unit. A rotary pump $\left(\mathrm{N}_{2}\right.$ exhaust 


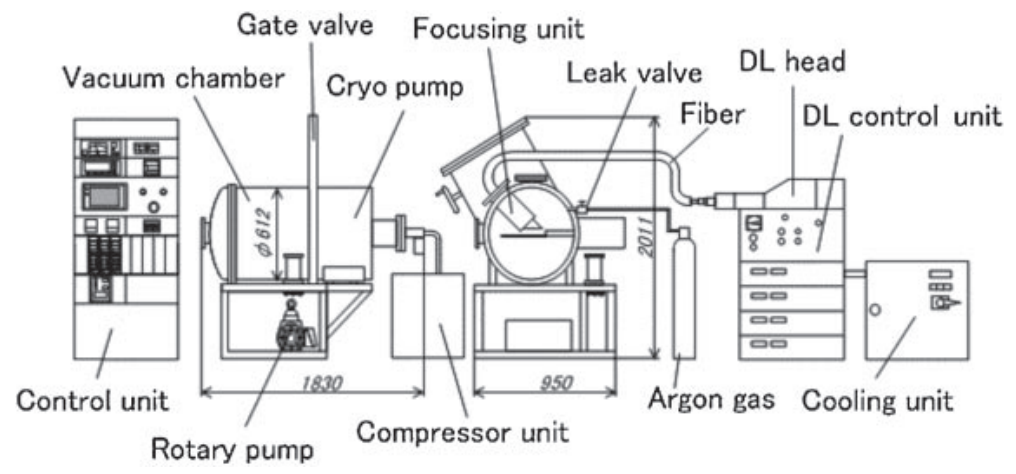

Fig. 1. High-vacuum DL welding experimental system.

rate: $0.65 \mathrm{~m}^{3} / \mathrm{min}$ ) and a cryopump (Ar exhaust rate: $8.4 \mathrm{~m}^{3} / \mathrm{s}$ ) were used as vacuum pumps. Approximately $2 \mathrm{~kW}$, mixed-wavelength laser light (wavelength: $808 \pm$ $10 \mathrm{~nm}, 940 \pm 10 \mathrm{~nm}$ ) was transmitted from the DL head to the focusing unit (120 mm focal length) by a $1.5 \mathrm{~mm}$ core-diameter optical fiber. Since the focusing unit is not designed to vacuum specifications, it was installed outside the vacuum chamber, as shown in Fig. 2(a). The laser light was introduced into the vacuum chamber from a quartz laser window (quartz window, diameter: $70 \mathrm{~mm}$, plate thickness: $8 \mathrm{~mm}$ ), passed through a quartz plate (quartz window, diameter: $70 \mathrm{~mm}$, plate thickness: $2.2 \mathrm{~mm}$ ) deposited at the tip of the focusing unit, and was irradiated onto a sample workpiece on a moving stage. The quartz plate was installed to protect the optical components (focusing unit, quartz laser window, etc.) from reduced transmittance, degradation, and damage caused by metal deposition. This study investigated a technique for preventing metal deposition onto optical components by installing a nozzle on this quartz plate. Figure 2(a) shows a focusing unit without a nozzle (hereafter, nozzleless unit) consisting of a quartz plate, a moving stage, and a workpiece that were used in past experiments. Figure 2(b) shows the focusing unit with a nozzle installed covering the quartz plate that was used in this experiment (hereafter, nozzle-equipped unit), and Fig. 2(c) shows a detailed diagram of the nozzle. A $D_{\mathrm{n}}$ nozzle diameter orifice, through which the laser light passes, was installed at the lower right tip of the nozzle and the effect of the nozzle outlet diameter on shielding vaporized metal from entering the nozzle was studied. In addition, shielding gas was blown from the nozzle and the effect of controlling or preventing metal deposition on the quartz plate was studied.

\subsection{Sample material and experimental method}

The sample workpiece was a SUS304 stainless steel plate (plate thickness: $3 \mathrm{~mm}$, plate width: $90 \mathrm{~mm}$, plate length: $80 \mathrm{~mm}$ ) with surface degreased when purchased. The vacuum chamber pressure was measured using a modified Bayard-Alpert ionization vacuum gauge, mounted $0.3 \mathrm{~m}$ from the welding position. After attaching the sample workpiece to the moving stage, the vacuum chamber was evacuated to $10^{-5} \mathrm{~Pa}$ and welding was performed. The welding method consisted of melt-run welding to melt the sample

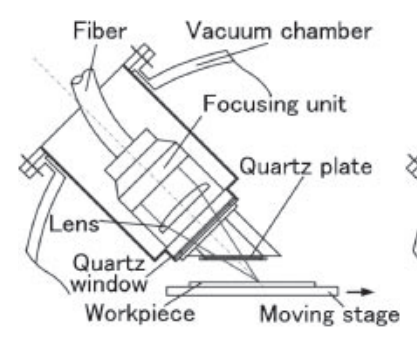

(a) Nozzleless unit

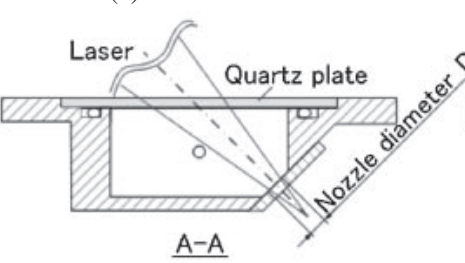

(c) Nozzle

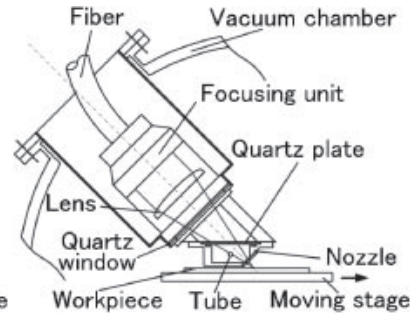

(b) Nozzle-equipped unit
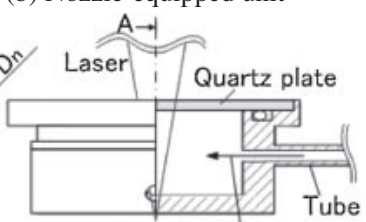

$A \rightarrow$ Shielding gas for preventing metal deposition

Fig. 2. Focusing unit and nozzle

surface. The welding speed was $2 \mathrm{~mm} / \mathrm{s}$, so that an approximately $60 \mathrm{~mm}$-long weld was made in the lengthwise direction at the center of the plate width in a welding time of approximately $30 \mathrm{~s}$. The laser irradiation conditions were an irradiation angle of $45^{\circ}$, just-focused with the focal point at the sample surface (the laser spot was elliptical, with a long axis of approximately $4 \mathrm{~mm}$ and a short axis of $3 \mathrm{~mm}$ ), and the observed laser power was $1.7 \mathrm{~kW}$. In welding experiments where shielding gas was blown from the nozzle, after attaching the sample workpiece to the moving table, the vacuum chamber was evacuated to $10^{-5} \mathrm{~Pa}$. The specified flow rate of shielding gas was then blown from the nozzle outlet and welding started with the vacuum chamber pressure being maintained at a constant pressure. The vacuum chamber pressure was the pressure corrected by a relative sensitivity coefficient that depends on metal vaporization and the type of shielding gas, and the shielding gas flow rate was expressed as the flow rate at STP conditions (i.e., $0^{\circ} \mathrm{C}, 1 \mathrm{~atm}$ ). The average transmittance of the area of the quartz plate transmitting the laser light (hereafter, laser transmission area) was the average of the transmittance values measured in the measurement wavelength range 808 to $940 \mathrm{~nm}$ using a spectrophotometer. The reduction in the transmittance of the laser transmission area due to 
Table 1. Relationship between nozzle diameter, condition of metal deposition on quartz plate and weld metal dimensions.

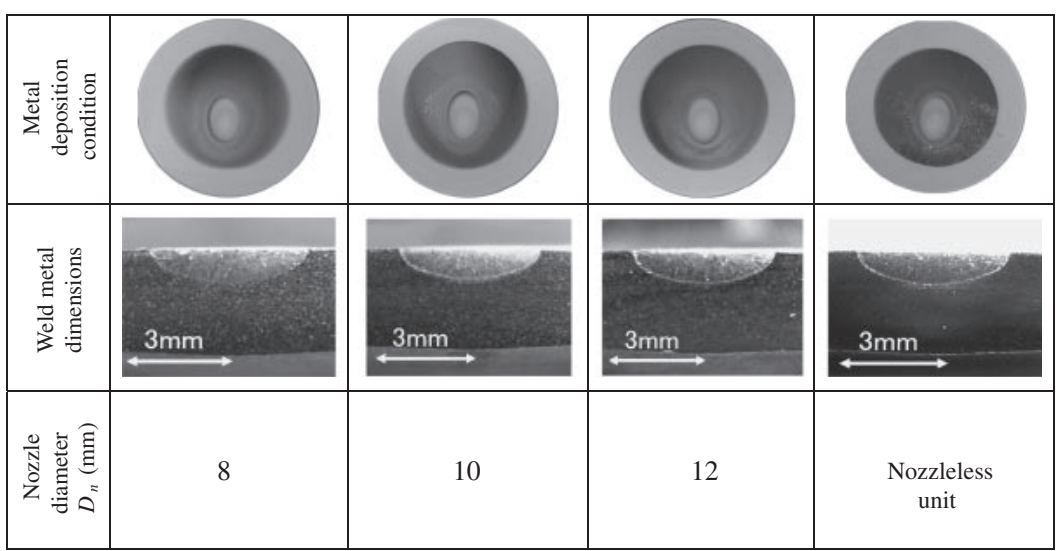

metal deposition was found as the difference between the average transmittances before and after welding. The weld metal dimensions were measured by observing the crosssectional macrostructure at a location $40 \mathrm{~mm}$ from the welding start point.

\section{Experimental Results and Discussion}

\subsection{Metal deposition shielding effect of nozzle}

To investigate the metal deposition shielding effect of the nozzle, welding experiments were performed using the nozzleless unit in Fig. 2(a) and using the nozzle-equipped unit in Fig. 2(b) without using shielding gas while using nozzle diameters $D_{\mathrm{n}}$ of 8,10 , and $12 \mathrm{~mm}$. When welding commences, metal vapor is produced from the weld pool and the vacuum chamber pressure suddenly increases. However, the pressure returns to a constant pressure determined by the quantity of metal vapor generated and the evacuation capacity of the vacuum pump. Under the present welding conditions, the pressure before welding $\left(10^{-5} \mathrm{~Pa}\right)$ started to increase to a constant pressure of $1.7 \times 10^{-3} \mathrm{~Pa}$ about $3 \mathrm{~s}$ after welding started and did not change until welding ended.

When metal melts in a low-pressure environment, metal vapor is produced and metal deposition occurs causing a metal deposition film to adhere to surfaces of surrounding objects. A metal deposition film formed on the surface of an optical component will absorb laser light and generate heat, damaging the optical component. Therefore, establishing a technique to prevent metal deposition on optical components is a major issue in the practical application of space laser welding techniques. Table 1 shows the relationship between the nozzle diameter $D_{\mathrm{n}}$, the metal deposition condition on the quartz plate after welding, and the weld dimensions (weld metal dimensions). This table also shows the results for a nozzleless unit. The experimental results in Table 1 show that neither the presence of a nozzle nor the nozzle diameter $D_{\mathrm{n}}$ had any effect on metal deposition or weld metal dimensions. The elliptical area that appears to be nearly transparent near the center of the quartz plate is the laser transmission area, where the metal deposition film

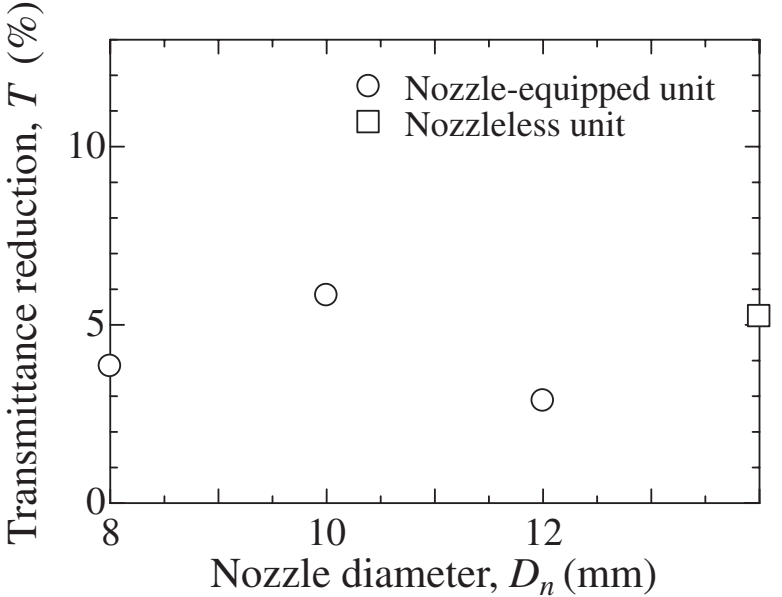

Fig. 3. Relationship between nozzle diameter and transmittance reduction.

has been revaporized. Outside the laser irradiated area, there is little revaporization because little heat is generated by absorption of the laser light, leaving a silver metal deposition film. The weld metal was elliptical in shape, and the width of the weld metal was approximately $3.8 \mathrm{~mm}$, which is slightly wider than the short axis of the laser irradiation region $(3 \mathrm{~mm})$, while the weld penetration depth was approximately $1.0 \mathrm{~mm}$.

The average transmittance of an unused quartz plate (measurement wavelength: $808-940 \mathrm{~nm}$ ) is $92 \%$. The laser transmission area degrades through repetition of metal deposition and absorption of the laser light by the metal deposition film which causes the film to revaporize. As a result, the transmittance is reduced and localized melting and cracking may develop. Figure 3 shows the relationship between the nozzle diameter and the transmittance reduction in the laser transmission area. The transmittance reduction showed nearly the same values in a range of approximately $3-6 \%$, irrespective of the nozzle diameter, and the results using a nozzleless unit (indicated by $\square$ ) showed nearly the same values.

In inclined laser irradiation welding experiments using the nozzleless unit in Fig. 2(a), we showed that the molecu- 
lar density distribution of the metal vapor produced from the weld pool has a spherical distribution following the cosine law. ${ }^{13)}$ Focusing on this kind of metal vaporization characteristic, the method of shielding a majority of metal vapor by tilting the nozzle at a $45^{\circ}$ angle was investigated in this study. However, the experimental results in Table 1 and Fig. 3 show that metal deposition on the quartz plate could not be controlled adequately even if only a portion of the vaporized metal vapor infiltrated the nozzle. This is thought to be due primarily to the long mean free path of iron gas molecules, and the high percentage of iron gas molecules reaching the quartz plate, due to the low vacuum chamber pressure of $1.7 \times 10^{-3} \mathrm{~Pa}$ (see Appendix 1).

\subsection{Effects of type of shielding gas on metal deposition on quartz plate and weld metal dimensions}

The effects of the supply and type of shielding gas on controlling metal deposition on the quartz plate were studied using the nozzle-equipped unit in Fig. 2(b) (nozzle diameter: $8 \mathrm{~mm}$ ). Welding was performed while supplying inert gases $\mathrm{Ne}, \mathrm{Ar}$, and $\mathrm{Kr}$ as the shielding gas at a low flow rate of $0.17 \mathrm{ml} / \mathrm{s}$ and blowing them from the nozzle outlet. The evacuation capacity of the vacuum pump varies depending on the gas used; the constant vacuum chamber pressures were $5.6 \times 10^{-3} \mathrm{~Pa}, 8.9 \times 10^{-3} \mathrm{~Pa}$, and $1.0 \times 10^{-2} \mathrm{~Pa}$ for $\mathrm{Ne}, \mathrm{Ar}$, and $\mathrm{Kr}$, respectively. These constant pressures did not change over $30 \mathrm{~s}$ of welding.

Table 2 shows the effects of the type of shielding gas on the metal deposition condition on the quartz plate after welding and the weld metal dimensions. Metal deposition was only slightly suppressed outside the laser transmission area with $\mathrm{Ne}$. However, control of metal deposition was confirmed using Ar and $\mathrm{Kr}$. It was found that, at the same gas flow rate, the metal deposition controlling effect was greater for a gas with a greater molecular weight. While this is not shown in the figure, the transmittance reduction in the laser transmission area was in the approximate range of $2-4 \%$, which is slightly lower than that when there was no shielding gas (approximately 3-6\%). A difference in transmittance reduction due to the type of gas could not be confirmed. In addition, a difference in the weld dimensions (weld metal dimensions) due to the gas type could not be confirmed. The weld metal was approximately $5.3 \mathrm{~mm}$ wide and the weld penetration depth was approximately $1.5 \mathrm{~mm}$, which is approximately $1.5 \mathrm{~mm}$ wider and $0.5 \mathrm{~mm}$ deeper than the weld metal dimensions in Table 1, when a shielding gas was not used. This result supports the fact that the laser power irradiated at the sample workpiece surface is increased by supplying shielding gas to the nozzle and blowing it from the nozzle outlet. The increase in the laser power irradiated at the sample workpiece surface occurs because the nozzle pressure is increased by the supply of shielding gas. This is thought to be due to the fact that increasing the pressure in the nozzle reduces the mean free path of iron gas molecules, reducing the percentage that reach the quartz plate, and thus controlling metal deposition (see Appendix 2). We hypothesize that the reason why it was not possible to confirm that the type of shielding gas had
Table 2. Relationship between shielding gas, metal deposition condition on quartz plate and weld metal dimensions.

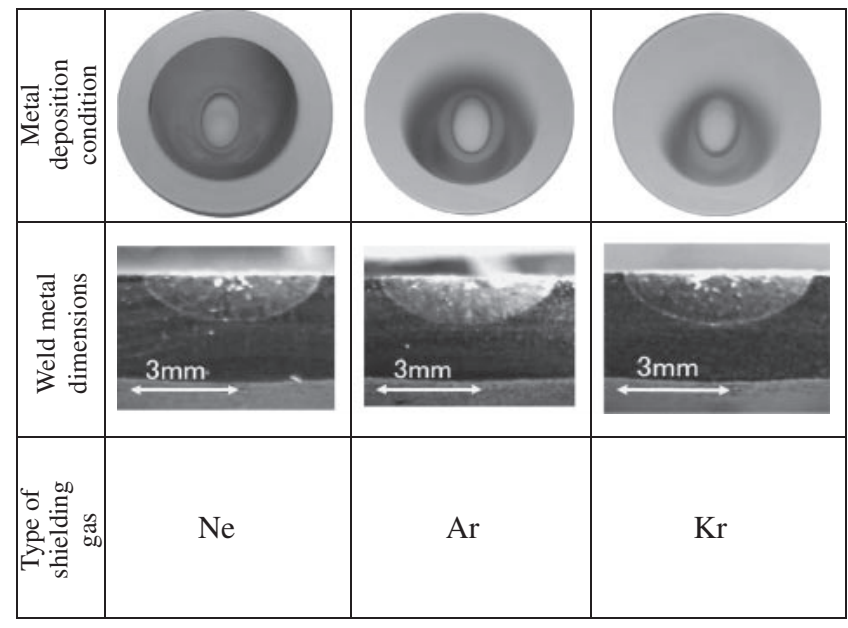

any effect on transmittance reduction or weld metal dimensions in experiments using very small flow rates $(0.17 \mathrm{ml} / \mathrm{s})$ of the inert gases $\mathrm{Ne}, \mathrm{Ar}$, and $\mathrm{Kr}$, is that metal deposition to the laser transmission area was insufficiently controlled because the gas flow rates were too low.

\subsection{Effects of Ar shielding gas flow rate on condition of metal deposition on quartz plate and weld metal dimensions}

An experiment was performed by welding while blowing $\mathrm{Ar}$ at gas flow rates in the range $0.17-1.67 \mathrm{ml} / \mathrm{s}$ from a 8-mm diameter nozzle outlet to study the effects of the flow rate of Ar shielding gas on the ability to control or prevent metal deposition on the quartz plate and the weld metal dimensions. The constant vacuum chamber pressure before starting welding was in the range $8.9 \times 10^{-3}$ to $5.7 \times 10^{-2}$ $\mathrm{Pa}$, which is comparable to the Ar flow rate. This constant pressure did not change during welding. It is known that less metal deposition occurs as the vacuum chamber pressure increases. Therefore, to study metal deposition prevention when Ar is supplied to the nozzle or blown from the nozzle outlet, welding experiments were performed at the same constant pressure when Ar was introduced from a leak valve located about $0.3 \mathrm{~m}$ from the welding area shown as in Fig. 1, and when Ar was blown from the nozzle outlet.

Table 3 shows the relationship between the Ar flow rate and the metal deposition condition on the quartz plate and the weld metal dimensions. The top photographs show the results when Ar was blown from the 8-mm diameter nozzle outlet, and the bottom photographs show the results when $\mathrm{Ar}$ was introduced from the leak valve. When Ar was blown from the nozzle outlet, the gas flow rate increased and the metal deposition decreased, with metal deposition prevented at flow rates of $0.83 \mathrm{ml} / \mathrm{s}$ and higher. On the other hand, when Ar was introduced from the leak valve, a metal deposition film adhered to the quartz plate even at flow rates of $0.83 \mathrm{ml} / \mathrm{s}$ and higher. This difference is the result of blowing Ar from the nozzle outlet. When Ar was blown from the nozzle outlet, the width and weld penetration depth of the weld metal increased slightly as the gas flow rate increased, 
Table 3. Effects of Ar gas flow rate on metal deposition condition on quartz plate and weld metal dimensions.

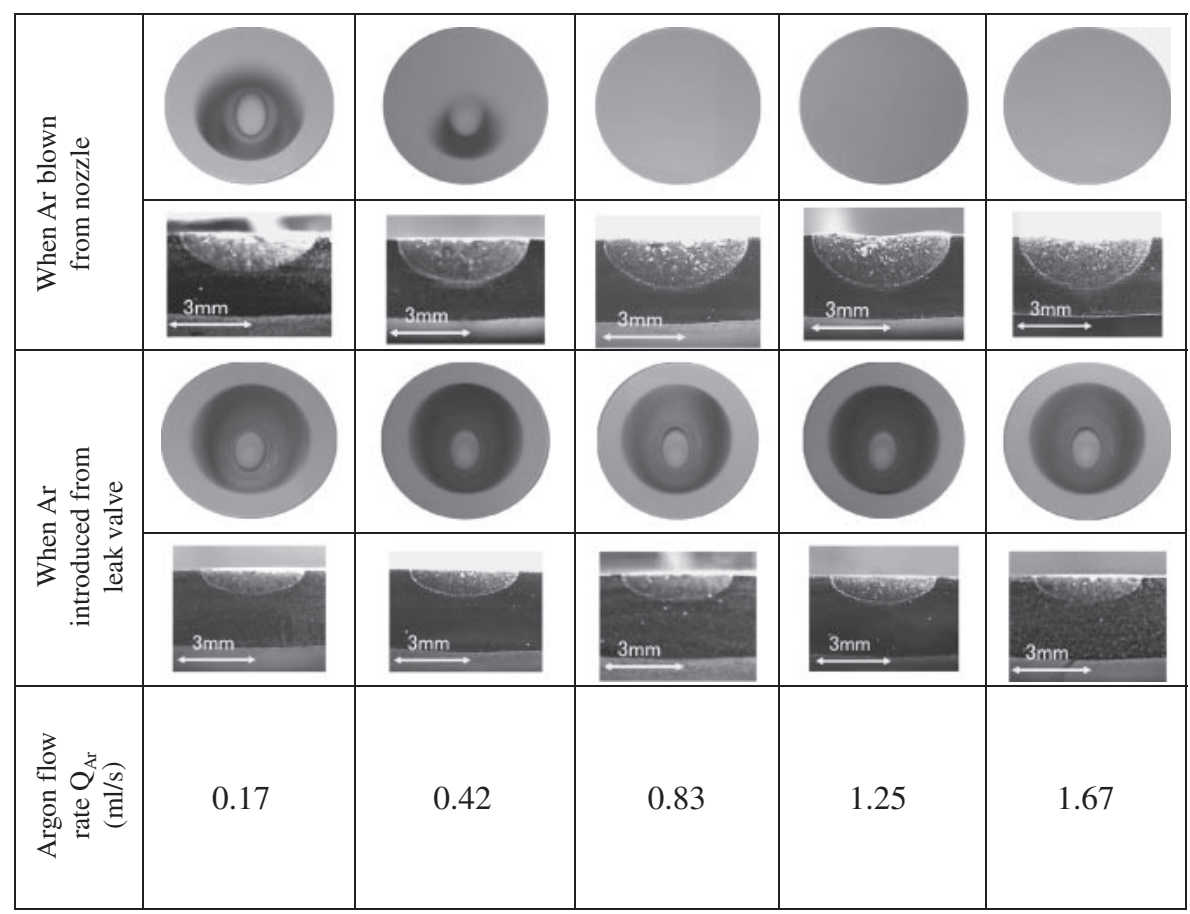

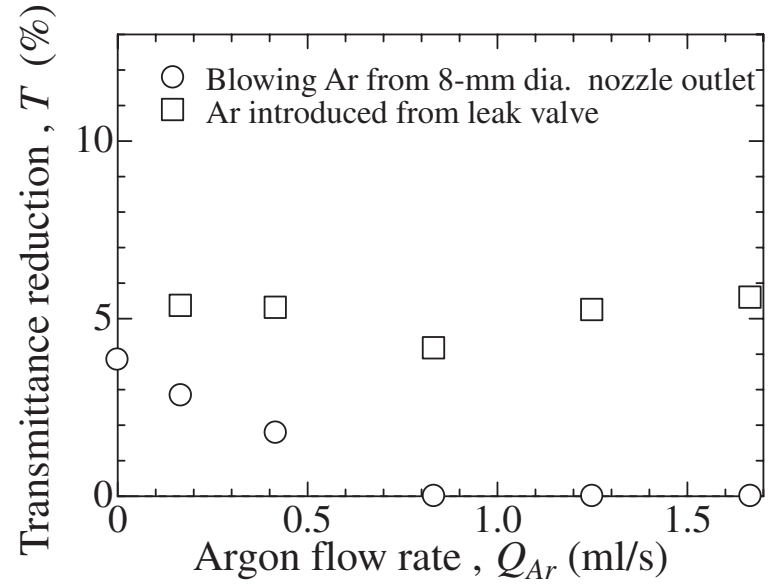

Fig. 4. Relationship between Ar gas flow rate and transmittance reduction.

but the dimensions remained the same at flow rates of $0.83 \mathrm{ml} / \mathrm{s}$ and higher. On the other hand, when Ar was introduced from the leak valve, the width and weld penetration depth of the weld metal were smaller, and the laser power at the sample workpiece was lower than when $\mathrm{Ar}$ was blown from the nozzle outlet, irrespective of the gas flow rate.

Figure 4 shows the effects of the Ar flow rate on the transmittance reduction in the laser transmission area. Blowing Ar from the 8 -mm diameter nozzle outlet (indicated by $\bigcirc$ symbols) reduced the transmittance reduction as the gas flow rate increased; the transmittance reduction became zero at flow rates of $0.83 \mathrm{ml} / \mathrm{s}$ and higher. On the other hand, when Ar was introduced from the leak valve (indicated by $\square$ symbols), nearly the same level of transmittance reduction, in the range of $4-6 \%$, was obtained irrespective of

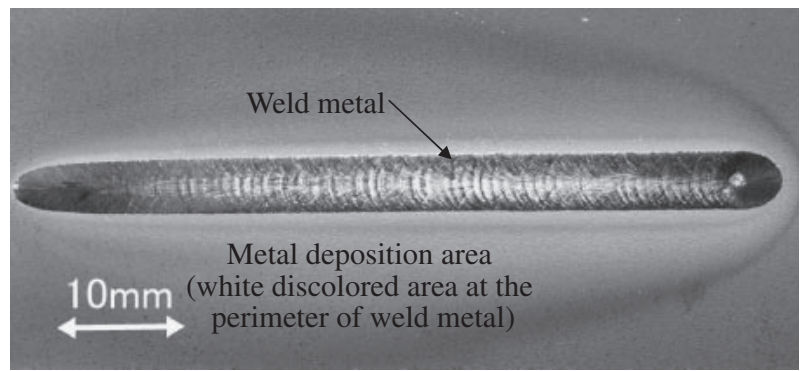

Fig. 5. Condition of metal deposition around weld metal.

the gas flow rate, and was almost the same as the 3-6\% transmittance reduction in Fig. 3 when no shielding gas was used. These results show that metal deposition on the quartz plate can be prevented by supplying Ar to the nozzle and blowing it from the nozzle outlet at a gas flow rate of $0.83 \mathrm{ml} / \mathrm{s}$ or higher. The nozzle pressure when a $0.83 \mathrm{ml} / \mathrm{s}$ Ar flow rate was supplied and blown from an 8-mm diameter nozzle was $16.9 \mathrm{~Pa}$, calculated according to the concept in Appendix 2. Consequently, under these laser welding conditions, metal deposition on the quartz plate and reduction in the transmittance in the laser transmission area can both be prevented, as long as the Ar pressure inside the nozzle is high (16.9 Pa or more) (Appendix 3).

Figure 5 shows the surface conditions on a sample workpiece welded with an Ar flow rate of $0.83 \mathrm{ml} / \mathrm{s}$. A metal deposition film (white discolored area at the perimeter of the weld metal) of adhered metal vapor was observed on the weld metal and its perimeter. The pressure ratio of the constant vacuum chamber pressure of $3.0 \times 10^{-2} \mathrm{~Pa}$ during welding and the nozzle pressure of $16.9 \mathrm{~Pa}$ is approximately $1.8 \times 10^{-3}$, a very small value. Therefore, the flow velocity coefficient is high with the velocity of Ar blown from the 


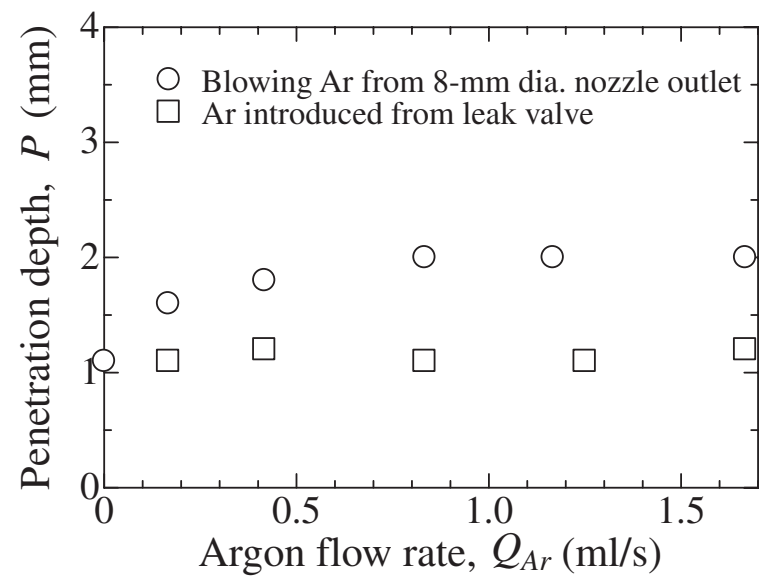

Fig. 6. Relationship between Ar gas flow rate and weld penetration depth.

nozzle outlet approaching the speed of sound. The Ar stream is thought to push the metal vapor back to the surface of the sample workpiece, causing the metal vapor film to adhere to the workpiece.

Figure 6 shows the relationship between the Ar flow rate and the weld penetration depth of the weld metal. When Ar is blown from the nozzle outlet (indicated by $\bigcirc$ symbols), the weld penetration depth increases as the gas flow rate increases, reaching a maximum of approximately $2 \mathrm{~mm}$ at flow rates of $0.83 \mathrm{ml} / \mathrm{s}$ and higher under the current laser welding conditions. In contrast, when introduced from the leak valve (indicated by $\square$ symbols), the weld penetration depth was approximately $1 \mathrm{~mm}$ regardless of the Ar flow rate, which was nearly the same weld penetration depth as that for the case shown in Fig. 3 when no shielding gas was introduced. These results show the same tendency as the effect of Ar flow rate on the transmittance reduction in the laser transmission area shown in Fig. 4.

This indicates that metal deposition on the quartz plate can be prevented by supplying Ar shielding gas to the nozzle and maintaining the nozzle pressure at $16.9 \mathrm{~Pa}$ or more. It also confirms that there is no damage to the laser transmission area of the quartz plate due to localized melting or cracking even when welding is performed for a total of $1 \mathrm{~h}$ or longer. The technique proposed by this study to prevent metal deposition by covering optical components with a nozzle and using a shielding gas can be applied to welding in space.

\section{Conclusion}

To enable practical use of DL welding technology in space, we must develop a technique to prevent metal deposition on optical components. Methods were studied for controlling or preventing metal deposition on the quartz plate at the tip of the focusing unit by covering it with a nozzle to shield it from metal vapor, and by supplying a shielding gas blown from the nozzle outlet. The following points were clarified by DL welding experiments at reduced pressure using SUS304 stainless steel as the sample material.
1) Metal deposition on the quartz plate can not be controlled sufficiently by installing a nozzle with an orifice diameter $D_{\mathrm{n}}=8-12 \mathrm{~mm}$, tilted at an angle of $45^{\circ}$, near the weld pool without using shielding gas.

2) When shielding gas is not used, the transmittance reduction of the laser transmission area of the quartz plate is in the range of approximately $3-6 \%$, regardless of the presence of a nozzle or the nozzle diameter.

3) Metal deposition on the quartz plate can be controlled and the transmittance reduction in the laser transmission area can be reduced when $\mathrm{Ne}, \mathrm{Ar}$, or $\mathrm{Kr}$ is supplied as a shielding gas and blown from the nozzle outlet.

4) A shielding gas with a higher molecular weight is more effective in controlling metal deposition outside the laser transmission area.

5) Ar shielding gas prevents metal deposition on the quartz plate and transmittance reduction in the laser transmission area is eliminated when the nozzle pressure is higher than $16.9 \mathrm{~Pa}$ (flow rate: $0.83 \mathrm{ml} / \mathrm{s}$, nozzle diameter: $8 \mathrm{~mm}$ ).

\section{References}

1) Paton, B. E.: Welding in Space, Welding Engineer, 57 (1972), pp. 2529.

2) Dzhanibekov, V. A., Zagrebelny, A. A., Gavrish, S. S., Stesin, V. V., Shelyagin, V. D., Yurchenko, N. N. and Markov, A. V.: Welding Equipment for Space Applications, Proc. Conf. "Welding in Space and the Construction of Space Vehicles by Welding," New Carrollton, Md., 1991, pp. 49-58.

3) Schollhammer, F. R.: Electron Beam Welder for Space, Nat. Sympo. Materials for Space Vehicle Use, 6th, Seattle, Wash., Society of Aerospace Material and Process Engineer, 1963, p. 51.

4) Nogi, K., Aoki, Y., Fujii, H. and Nakata, K.: Behavior of Bubbles in Weld under Microgravity, Acta Materialia, 46 (1998), pp. 4405-4416.

5) Johnsen, R.: Space Welding Experiment Postponed Indefinitely, Welding J., 76(4) (1997), p. 22.

6) Suita, Y., Tsukuda, T., Takagi, T., Ohji, T. and Masubuchi, K.: A Study on Gas Tungsten Arc Welding in Space (1st Report), Weld. Int., 8 (1994), pp. 269-273.

7) Suita, Y., Ohara, M., Sogawa, H., Matsusita, K., Shoubako, S., Terajima, N., Tsukuda, T., Masubuchi, K. and Yamauchi, S.: Welding Experiments on Aluminum Pipe by Space GHTA Welding in AircraftBorne Simulated Space Environment, J. Jpn. Weld. Soc., 25 (2007), pp. 494-500 (in Japanese).

8) Yoshida, K., Nishikawa, H., Ohji, T., Suita, Y. and Masubuchi, K.: Fundamental Characteristics of Hollow Cathode Arc Welding, J. Jpn. Weld. Soc., 20 (2002), pp. 47-52 (in Japanese).

9) Shoubaka, S., Ohta, M. and Ohji, T.: Characteristics of Column on Hollow Cathode Arc, J. Jpn. Weld. Soc., 23 (2005), pp. 270-275 (in Japanese).

10) Kaukler, W. F. and Workman, G. L.: Laser Welding in Space, Proc. Conf. "Welding in Space and the Construction of Space Vehicles by Welding," New Carrollton, Md., 1991, pp. 318-334.

11) Suita, Y., Kurokawa, Y., Shoubako, S., Satoh, J., Tabakodani, A., Fujisawa, S. and Imagawa, K.: Proposal of Space LD Process, J. Jpn. Laser Processing. Soc., 9 (2002), pp. 29-33 (in Japanese).

12) Suita, Y., Tabakodani, E., Sugiyama, S., Terajima, N., Tsukuda, Y., Fujisawa, S. and Imagawa, K.: Development of Space DL Welding Process for Construction and Repair of Space Structure in Space, Trans. Jpn. Soc. Aeronaut. Space Sci., 48 (2005), pp. 86-91.

13) Suita, Y., Tanabe, K., Terajima, N., Tsukuda, Y. and Imagawa, K.: Welding Phenomenon of Stainless Steel by the Space Diode Laser Welding Process in Various Pressures, J. Jpn. Soc. Aeronaut. Space Sci., 53 (2005), pp. 426-430 (in Japanese). 
14) Yamashina, T. and Hirohata, Y.: Vacuum Technology, Kyoritsu Press, Tokyo, 1991, p. 34, Eq. (2.56) (in Japanese).

15) Yamashina, T. and Hirohata, Y.: Vacuum Technology, Kyoritsu Press, Tokyo, 1991, p. 36, Fig. 2.11 (in Japanese).

16) Yamashina, T. and Hirohata, Y.: Vacuum Technology, Kyoritsu Press, Tokyo, 1991, p. 63, Eq. (2.107) (in Japanese).

\section{Appendix}

\section{Appendix 1}

When the mean free path ${ }^{14)}$ of iron gas molecules (atomic diameter: $2.7 \times 10^{-10} \mathrm{~m}$ ), the main component in SUS304 stainless steel, at vacuum chamber internal pressure of $1.7 \times 10^{-3} \mathrm{~Pa}$ and a temperature of $20^{\circ} \mathrm{C}$, is approximated calculated using the equation $\lambda_{\mathrm{Fe}}=3.1 \times 10^{-24} \mathrm{~T} / \mathrm{d}^{2} \mathrm{P}$ $[T$ : temperature $(\mathrm{K}), d$ : gas molecular diameter $(\mathrm{m}), P$ : pressure $(\mathrm{Pa})]$, it is found to be about $7.33 \mathrm{~m}$. The Knudsen number $\lambda_{\mathrm{Fe}} / D$ for a typical vacuum chamber diameter $D$ of $0.6 \mathrm{~m}$ is $\lambda_{\mathrm{Fe}} / D=7.33 / 0.6=12.2>0.3$. Consequently, the flow of iron gas molecules can be treated as a molecular flow. In this case, the percentage $P_{\mathrm{D}}$ of iron gas molecules reaching the quartz plate (separated by a minimum distance of $0.03 \mathrm{~m}$ from the weld pool) is estimated ${ }^{15)}$ to be $P_{\mathrm{D}}=0.996$. Thus, it can be assumed that most of the iron gas molecules infiltrating the nozzle reach the quartz plate. In addition to collisions between iron gas molecules, it is also strictly necessary to consider collisions with nitrogen and oxygen molecules, etc. in any residual air, but because their molecular diameters are of the order of $10^{-10}$ and are not extremely different, the mean free path can be approximated based on the mean free path from collisions only between iron gas molecules.

\section{Appendix 2}

A model is considered in which there are two chambers, $\mathrm{A}$ and $\mathrm{B}$, separated by an orifice, and a constant gas flow rate is supplied to chamber A from the opposite side of the orifice from chamber $\mathrm{A}$, and then evacuated by a vacuum pump from the opposite side of the orifice from chamber B, blowing the gas from the orifice (nozzle outlet) into chamber $\mathrm{B}$. The pressure $P_{\mathrm{A}}$ in chamber $\mathrm{A}$ in the model can be expressed by the equation $P_{\mathrm{A}}=Q / C+P_{\mathrm{B}}\left[P_{\mathrm{A}}\right.$ : pressure of chamber $\mathrm{A}(\mathrm{Pa}), P_{\mathrm{B}}$ : pressure of chamber $\mathrm{B}(\mathrm{Pa}), Q$ : gas flow rate $\left(\mathrm{Pa} \cdot \mathrm{m}^{3} / \mathrm{s}\right), C$ : orifice conductance $\left.\left(\mathrm{m}^{3} / \mathrm{s}\right)\right]$. The conductance $C$ is determined by the nozzle outlet surface area, gas constant, molecular weight, and temperature. ${ }^{16)}$ We estimated the nozzle pressure $P_{\mathrm{N}}$ under the experimental conditions in Section 3.2, where the nozzle internal pressure $P_{\mathrm{N}}$ is the pressure $P_{\mathrm{A}}$ of chamber $\mathrm{A}$ and the measured vacuum chamber pressure is the pressure $P_{\mathrm{B}}$ of chamber B. The nozzle internal pressures $P_{\mathrm{N}}$, in cases where $\mathrm{Ne}$, $\mathrm{Ar}$, or $\mathrm{Kr}$ shielding gas was supplied to the nozzle at a flow rate of $0.17 \mathrm{ml} / \mathrm{s}$ and blown from the $8-\mathrm{mm}$ diameter nozzle outlet into the vacuum chamber, were $2.47,3.47$, and 5.0 Pa, respectively. The mean free paths of each gas molecule at these pressures were $4.94 \times 10^{-3}, 1.98 \times 10^{-3}$, and $1.05 \times$ $10^{-3} \mathrm{~m}$, respectively (Appendix 1 ). The percentages of iron gas molecules among these various gas molecules reaching the quartz plate (located $0.03 \mathrm{~m}$ from the weld pool) (assuming that iron gas molecules and gas molecules are the same size) for $\mathrm{Ne}, \mathrm{Ar}$, and $\mathrm{Kr}$ were found to be $2.3 \times 10^{-3}$, $2.62 \times 10^{-7}$, and $3.90 \times 10^{-13}$, respectively. These percentages for iron gas molecules reaching the quartz plate are much lower than in Section 3.1 when no shielding gas was used. In addition, at the same gas flow rate, the percentage of iron gas molecules reaching the quartz plate decreases with increasing molecular weight of the gas. These results show the same tendencies as the experimental results in Table 2.

\section{Appendix 3}

The mean free path of Ar gas molecules at $\mathrm{Ar} 16.9 \mathrm{~Pa}$ is $4.06 \times 10^{-4} \mathrm{~m}$. The calculated percentage of iron gas molecules in that Ar reaching the quartz plate located $0.03 \mathrm{~m}$ from the weld pool is $8.11 \times 10^{-33}$. 